\title{
Auto-regulation in the powerhouse
}

\section{Mitochondrial flashes have a central role in ensuring that ATP levels remain constant in heart cells.}

\section{HELENA M VIOLA AND LIVIA C HOOL}

Related research article Wang $X$, Zhang $X$,

Wu D, Huang Z, Hou T, Jian C, Yu P, Lu F,

Zhang R, Sun T, Li J, Qi W, Wang Y, Gao F,

Cheng H. 2017. Mitochondrial flashes

regulate ATP homeostasis in the Heart. eLife

6:e23908. doi: 10.7554/eLife. 23908

A denosine triphosphate, or ATP for short, provides the energy that is needed for countless processes in the body. It is vital that the level of ATP in cells remains constant, especially when the demand for energy increases. This is particularly true in the heart, where energy demand can increase by a factor of 5-10 during stressful situations, yet the ATP concentration remains remarkably consistent (Balaban et alo, 1986; Neely et alo, 1973; Matthews et alo, 1981; Allue et alo, 1996).

Despite decades of research, it has remained unclear how cells keep their ATP levels stable. Now, in eLife, Heping Cheng of Peking University and colleagues - with Xianhua Wang, Xing Zhang and Di Wu as joint first authors - report that a process termed mitochondrial flash or mitoflash plays a critical role in regulating ATP concentration in the heart (Wang et al., 2017).

ATP production occurs in several stages inside mitochondria, where a flow of electrons down the mitochondrial 'electron transport chain' creates an electro-chemical gradient across the inner membrane of mitochondria. In the first stage, calcium is transported across the inner membrane into the inner mitochondrial chamber or matrix, and used in a process known as the citric acid cycle to generate high-energy electrons. These electrons then enter the electron transport chain and travel along the inner membrane to an enzyme called ATP-synthase that produces ATP. As a by-product of this process, molecules called reactive oxygen species are formed when electrons that leak from the electron transport chain go on to react with oxygen molecules. Although high levels of reactive oxygen species lead to cell death and disease, low levels of these species are important for regulating normal cell processes.

Recent research has shown that mitochondria exhibit brief events called mitoflashes. These involve multiple concurrent changes within the mitochondria, including a burst in the production of reactive oxygen species, as well as changes in the $\mathrm{pH}$ of the mitochondrial matrix, the oxidative redox state and the membrane potential (Wang et al., 2008, 2016). Mitoflashes depend on an intact electron transport chain and are thought to help regulate energy metabolism.

Using cells isolated from mouse heart muscle, Wang et al. demonstrated that it is the frequency of the mitoflashes - rather than the amplitude - that regulates ATP production. When the heart cells were exposed to drivers of the citric acid cycle to mimic increased energy metabolism, the mitoflashes occurred more frequently, while ATP production remained constant. However, when antioxidants were applied, the frequency of mitoflashes decreased, which led to an increase in ATP production. These 
findings suggest that mitoflash activity responds to changes in energy metabolism to negatively regulate ATP production.

When electrical stimuli were applied to make the heart cells contract more quickly and increase the demand for ATP, the frequency of mitoflashes decreased, while the cellular ATP content remained constant. It appears that when a lot of energy is needed, changes in the frequency of the mitoflashes regulate ATP production in a way that supports survival. Indeed, the results revealed that when mitoflash frequency decreased, the ATP concentration or set-point increased. This suggests that mitoflash activity may act as an ATP set-point regulator that responds to changes in energy supply and demand in order to maintain ATP homeostasis in the heart (see Figure 6 in Wang et al., 2017).

Wang et al. provide the first mechanistic insight into a potential trigger that links changes in mitoflash frequency and regulation of the ATP set-point in the heart. Previous studies have identified three possible triggers of mitoflashes: calcium located in the mitochondrial matrix, reactive oxygen species and protons (Hou et al., 2013; Wang et al., 2016). Wang et al. propose that calcium is unlikely to play a significant role in the regulation of mitoflash frequency. And since electrical stimulation did not significantly change the amount of reactive oxygen species produced by the mitochondria, they focused their attention on protons as a trigger of mitoflashes.

It is known that protons can leak through the ATP-synthase and return to the mitochondrial matrix, and it has been shown that a pro-survival protein called $\mathrm{Bcl}-\mathrm{xL}$ plays a role in regulating this proton leak (Alavian et al., 2011; Chen et al., 2011). Now, Wang et al. show that an increase in $\mathrm{BCl}-\mathrm{xL}$ prevents proton leaks and reduces the frequency of mitoflashes, while the ATP set-point increases. When there is a decrease in Bcl-xL protein, the opposite occurs. Based on these findings, Wang et al. propose that proton leaks may be a bi-directional trigger of mitoflashes and cellular ATP homeostasis.

Overall, Wang et al. demonstrate that mitoflash frequency negatively regulates ATP production in a compensatory, pro-survival manner, and that a high ATP demand induces a small and brief increase in calcium. These results are consistent with previous work characterizing mitoflashes (Wang et al., 2008) and the role of mitochondria in the development of diseases in the heart (Viola et al., 2007; Seenarain et alı, 2010). Future studies may provide more insight into how mitoflashes regulate ATP homeostasis during the development of heart diseases.

Helena M Viola is in the School of Human Sciences, The University of Western Australia, Crawley, Australia

Livia C Hool is in the School of Human Sciences, The University of Western Australia, Crawley, Australia, and the Victor Chang Cardiac Research Institute, Sydney, Australia livia.hool@uwa.edu.au

\section{(Dib) http://orcid.org/0000-0001-7758-5252}

Competing interests: The authors declare that no competing interests exist.

Published 10 July 2017

\section{References}

Alavian KN, Li H, Collis L, Bonanni L, Zeng L, Sacchetti S, Lazrove E, Nabili P, Flaherty B, Graham M, Chen Y, Messerli SM, Mariggio MA, Rahner C, McNay E, Shore GC, Smith PJ, Hardwick JM, Jonas EA. 2011. Bcl-xL regulates metabolic efficiency of neurons through interaction with the mitochondrial F1FO ATP synthase. Nature Cell Biology 13:1224-1233. doi: 10.1038/ ncb2330, PMID: 21926988

Allue I, Gandelman O, Dementieva E, Ugarova N, Cobbold P. 1996. Evidence for rapid consumption of millimolar concentrations of cytoplasmic ATP during rigor-contracture of metabolically compromised single cardiomyocytes. Biochemical Journal 319 (Pt 2):463469. doi: 10.1042/bj3190463, PMID: 8912682

Balaban RS, Kantor HL, Katz LA, Briggs RW. 1986. Relation between work and phosphate metabolite in the in vivo paced mammalian heart. Science 232:11211123. doi: 10.1126/science.3704638, PMID: 3704638 Chen YB, Aon MA, Hsu YT, Soane L, Teng $X$, McCaffery JM, Cheng WC, Qi B, Li H, Alavian KN, Dayhoff-Brannigan M, Zou S, Pineda FJ, O'Rourke B, Ko YH, Pedersen PL, Kaczmarek LK, Jonas EA, Hardwick JM. 2011. Bcl-xL regulates mitochondrial energetics by stabilizing the inner membrane potential. The Journal of Cell Biology 195:263-276. doi: 10.1083/jcb.201108059, PMID: 21987637 Hou T, Zhang X, Xu J, Jian C, Huang Z, Ye T, Hu K, Zheng M, Gao F, Wang X, Cheng H. 2013. Synergistic triggering of superoxide flashes by mitochondrial $\mathrm{Ca} 2$ + uniport and basal reactive oxygen species elevation. Journal of Biological Chemistry 288:4602-4612. doi: 10.1074/jbc.M112.398297, PMID: 23283965 Matthews PM, Bland JL, Gadian DG, Radda GK. 1981. The steady-state rate of ATP synthesis in the perfused rat heart measured by 31P NMR saturation transfer. Biochemical and Biophysical Research Communications 103:1052-1059. doi: 10.1016/0006291X(81)90915-3, PMID: 7332573

Neely JR, Rovetto MJ, Whitmer JT, Morgan HE. 1973. Effects of ischemia on function and metabolism of the isolated working rat heart. The American Journal of Physiology 225:651-658. PMID: 4726499

Seenarain V, Viola HM, Ravenscroft G, Casey TM, Lipscombe RJ, Ingley E, Laing NG, Bringans SD, Hool LC. 2010. Evidence of altered guinea pig ventricular cardiomyocyte protein expression and growth in 
response to a $5 \mathrm{~min}$ in vitro exposure to $\mathrm{H}(2) \mathrm{O}(2)$. Journal of Proteome Research 9:1985-1994. doi: 10. 1021/pr9011393, PMID: 20131912

Viola HM, Arthur PG, Hool LC. 2007. Transient exposure to hydrogen peroxide causes an increase in mitochondria-derived superoxide as a result of sustained alteration in L-type Ca2+ channel function in the absence of apoptosis in ventricular myocytes.

Circulation Research 100:1036-1044. doi: 10.1161/01. RES.0000263010.19273.48, PMID: 17347474

Wang W, Fang H, Groom L, Cheng A, Zhang W, Liu J, Wang X, Li K, Han P, Zheng M, Yin J, Wang W,

Mattson MP, Kao JP, Lakatta EG, Sheu SS, Ouyang K,
Chen J, Dirksen RT, Cheng H. 2008. Superoxide flashes in single mitochondria. Cell 134:279-290. doi: 10.1016/j.cell.2008.06.017, PMID: 18662543 Wang $X$, Zhang $X$, Huang Z, Wu D, Liu B, Zhang R, Yin R, Hou T, Jian C, Xu J, Zhao Y, Wang Y, Gao F, Cheng H. 2016. Protons trigger mitochondrial flashes.

Biophysical Journal 111:386-394. doi: 10.1016/j.bpj. 2016.05.052, PMID: 27463140

Wang $X$, Zhang X, Wu D, Huang Z, Hou T, Jian C, Yu P, Lu F, Zhang R, Sun T, Li J, Qi W, Wang Y, Gao F, Cheng H. 2017. Mitochondrial flashes regulate ATP homeostasis in the Heart. eLife 6:e23908. doi: 10. 7554/eLife. 23908 